\title{
High expression of gastrin-releasing peptide receptors in the vascular bed of urinary tract cancers: promising candidates for vascular targeting applications
}

\author{
Achim Fleischmann, Beatrice Waser and Jean Claude Reubi
}

Division of Cell Biology and Experimental Cancer Research, Institute of Pathology, University of Bern, Murtenstrasse 31, PO Box 62, $\mathrm{CH}-3010$ Bern, Switzerland

(Correspondence should be addressed to J C Reubi; Email: reubi@pathology.unibe.ch)

\begin{abstract}
Tumoral gastrin-releasing peptide (GRP) receptors are potential targets for diagnosis and therapy using radiolabeled or cytotoxic GRP analogs. GRP-receptor overexpression has been detected in endocrine-related cancer cells and, more recently, also in the vascular bed of selected tumors. More information on vascular GRP-receptors in cancer is required to asses their potential for vascular targeting applications. Therefore, frequent human cancers $(n=368)$ were analyzed using in vitro GRP-receptor autoradiography on tissue sections with the ${ }^{125} \mathrm{I}-\left[\mathrm{Tyr}^{4}\right]$-bombesin radioligand and/or the universal radioligand ${ }^{125} \mathrm{I}-\left[\mathrm{D}-\mathrm{Tyr}^{6}, \beta-\mathrm{Ala}^{11}\right.$, $\mathrm{Phe}^{13}$, Nle $\left.{ }^{14}\right]$-bombesin(6-14). GRPreceptor expressing vessels were evaluated in each tumor group for prevalence, quantity (vascular score), and GRP-receptor density. Prevalence of vascular GRP-receptors was variable, ranging from $12 \%$ (prostate cancer) to $92 \%$ (urinary tract cancer). Different tumor types within a given site had divergent prevalence of vascular GRP-receptors (e.g. lung: small cell cancer: 0\%; adenocarcinoma: $59 \%$; squamous carcinoma: $83 \%$ ). Also the vascular score varied widely, with the highest score in urinary tract cancer (1.69), moderate scores in lung (0.91), colon (0.88), kidney (0.84), and biliary tract (0.69) cancers and low scores in breast $(0.39)$ and prostate $(0.14)$ cancers. Vascular GRP-receptors were expressed in the muscular vessel wall in moderate to high densities. Normal non-neoplastic control tissues from these organs lacked vascular GRPreceptors. In conclusion, tumoral vessels in all evaluated sites express GRP-receptors, suggesting a major biological function of GRP-receptors in neovasculature. Vascular GRPreceptor expression varies between the tumor types indicating tumor-specific mechanisms in their regulation. Urinary tract cancers express vascular GRP-receptors so abundantly, that they are promising candidates for vascular targeting applications.
\end{abstract}

Endocrine-Related Cancer (2009) 16 623-633

\section{Introduction}

Targeting the tumor vascular bed is a novel clinical approach for tumor imaging and therapy (Thorpe et al. 2003, Brack et al. 2004). The therapeutical strategies comprise a) occlusion or destruction of established tumor vessels with rapid shutdown of the blood supply and subsequent tumor necrosis and b) inhibition of the development of a functional neovasculature
(Narazaki \& Tosato 2005) that is essential for tumor growth beyond 1-2 mm (Auguste et al. 2005). The most critical point in this concept is specificity, in order to avoid adverse effects to normal tissue blood supply (Narazaki \& Tosato 2005). Therefore, a precondition for successfully targeting the tumor vascular bed is the identification of molecules which are specifically overexpressed in these vessels. 
Peptide receptors are overexpressed in the neoplastic cells of different cancers but also in the tumor vascular bed of some cancers (Reubi et al. 1996, Fleischmann et al. 2000, 2005, 2007, Korner \& Reubi 2007, Otrock et al. 2007). Gastrin-releasing peptide (GRP), belonging to the family of bombesin-like peptides (Jensen et al. 2008), not only stimulates cancer growth through GRP-receptors in neoplastic cells (Cuttitta et al. 1985, Bologna et al. 1989, Yano et al. 1992) but also has been shown to be implicated in neoangiogenesis in several cancer models (Levine et al. 2003a,b, Bajo et al. 2004, Heuser et al. 2005, Kanashiro et al. 2005, 2007, Stangelberger et al. 2005, Kang et al. 2007). This may suggest that the corresponding receptor is systematically expressed in tumor vascular beds and plays an important biological function. Therefore, we explored GRP-receptor expression in a large number of different cancers from the breast, lung, prostate, kidney, colon, urinary tract, and biliary tract with in vitro autoradiography on human tissue sections using ${ }^{125} \mathrm{I}-\left[\mathrm{Tyr}^{4}\right]$-bombesin and/or ${ }^{125} \mathrm{I}-\left[\mathrm{D}-\mathrm{Tyr}^{6}, \beta-\mathrm{Ala}^{11}, \mathrm{Phe}^{13}, \mathrm{Nle}^{14}\right]$-bombesin (6-14) as radioligands for GRP-receptors. Information about prevalence and quantity of GRP-receptor expressing tumor vessels and density of expressed GRP-receptors in these frequent cancers is particularly important to determine the potential value of the numerous recently developed radiolabeled and nonradiolabeled cytotoxic bombesin analogs (Zhang et al. 2004, 2007, Engel et al. 2005, Nock et al. 2005, Lantry et al. 2006, Moody et al. 2006, Patel et al. 2006, de Visser et al. 2007, Waser et al. 2007) for in vivo vascular targeted clinical applications.

\section{Materials and methods}

\section{Tissues}

All tissue samples were immediately frozen after surgery and stored at $-80{ }^{\circ} \mathrm{C}$. Tissue samples of the following 368 primary tumors were analyzed: 134 breast cancers (113 invasive ductal carcinomas, 21 invasive lobular carcinomas); 57 lung cancers (29 squamous carcinomas, 17 adenocarcinomas, two large cell carcinomas, nine small cell carcinomas (SCLC)); 50 prostate cancers (acinar adenocarcinomas); 46 colon cancers (colorectal type); 32 renal cell cancers (28 clear cell carcinomas, four papillary carcinomas); 26 urinary tract cancers (invasive urothelial carcinomas; 25 from the urinary bladder, one from the renal pelvis); 23 cancers of the biliary tract (cholangiocarcinomas). In addition, samples of non-neoplastic tissues were tested (breast: 5 , lung: 48 , prostate: 26 , kidney: 4 , colon: 30 , biliary tract: 3 , urinary tract: 5 ). The tested tumors originated either from samples investigated previously for other receptors and collected in accordance with the required international ethical guidelines or from samples collected prospectively at the Institute of Pathology, University of Bern, following the principles of the Helsinki Declaration, including informed consent and approval by the Institutional Review Board.

\section{Receptor autoradiography}

We used ${ }^{125} \mathrm{I}$-[Tyr $\left.{ }^{4}\right]$-bombesin as radioligand, which is known to preferentially label GRP-receptors (Vigna et al. 1987). For autoradiography, $20 \mu \mathrm{m}$ thick cryostat tissue sections were processed as described previously (Reubi et al. 2002, Reubi \& Waser 2003). They were incubated with ${ }^{125} \mathrm{I}-\left[\mathrm{Tyr}^{4}\right]$-bombesin $(2000 \mathrm{Ci} / \mathrm{mmol}$; Anawa, Wangen, Switzerland) in a concentration of $100 \mathrm{pM}$ in the presence or absence of $0.1 \mu \mathrm{m}$ bombesin for $1 \mathrm{~h}$ at room temperature. Complete inhibition curves were generated in selected tissues by incubating consecutive sections in the presence of increasing amounts of non-radioactive GRP, bombesin or somatostatin-28 (Bachem, Bubendorf, Switzerland). After washing, the sections were placed in apposition to Biomax MR films (Kodak) and exposed for 7 days in $\mathrm{X}$-ray cassettes. The density of the GRP-receptors was quantified with a computer-assisted image processing system, as described previously (Reubi et al. 2002, Reubi \& Waser 2003). The reported density value for a given sample consisted of the mean of GRP-receptor determination in at least five positive vessels. In selected cases, the bombesin receptor subtype was evaluated in vessels using the universal radioligand ${ }^{125}{ }^{\text {I-[D-Tyr }}{ }^{6}, \beta$-Ala ${ }^{11}, \mathrm{Phe}^{13}, \mathrm{Nle}^{14}$ ]-bombesin(6-14; $2000 \mathrm{Ci} / \mathrm{mmol}$; Anawa) at a concentration of $20 \mathrm{pM}$. Displacement experiments were performed in consecutive sections in presence of $50 \mathrm{nM}$ of each of the unlabeled competitors [D-Tyr ${ }^{6}, \beta-\mathrm{Ala}^{11}, \mathrm{Phe}^{13}, \mathrm{Nle}^{14}$ ]bombesin(6-14), GRP and neuromedin B (NMB) and compared with total binding (in the absence of any competitor peptide).

To compare the incidence of GRP-receptor positive vessels between the various tumor groups, a vascular score was determined as previously described (Fleischmann et al. 2007). Briefly, in each tumor, the region with the highest incidence of GRP-receptor positive vessels was selected and the number of GRPreceptor positive vessels was determined in a visual field of $19 \mathrm{~mm}^{2}$ : 1-10 GRP-receptor positive vessels: grade 1; 11-30 GRP-receptor positive vessels: grade 2; more than 30 GRP-receptor positive vessels: grade 3; no GRP-receptor positive vessels present: grade 0 . 
The vascular score was defined as the mean of the grades from all tumors belonging to a particular tumor group.

\section{Results}

Cancers expressing GRP-receptors in their vascular bed were identified in all evaluated anatomical sites, namely in the breast, lung, prostate, kidney, colon, urinary, and biliary tract (Table 1). However, the prevalence of these GRP-receptor expressing tumorassociated vessels varied widely between these sites: it was $92 \%$ in urinary tract cancers, $88 \%$ in colon cancer, $60 \%$ in lung cancer, $57 \%$ in biliary tract cancer, $53 \%$ in renal cancer, $31 \%$ in breast cancer, and $12 \%$ in prostate cancer. A further important observation concerned the prevalence of these vessels in different tumor types of a given anatomical site. In the breast, the prevalence of GRP-receptor expressing vessels was similar in the two different tumor types (invasive ductal carcinoma $31 \%$, invasive lobular carcinoma 33\%). By contrast, the different cancer types of the lung showed a wide variability in the prevalence of such vessels ranging from $0 \%$ in SCLC over 59\% in adenocarcinomas to $83 \%$ in squamous carcinomas (Table 1).

While the prevalence merely reflects the percentage of tumors expressing vascular GRP-receptors within a given tumor group, the vascular score, defined as the number of GRP-receptor positive vessels per tumor area in the region of the highest incidence (see Materials and methods), is a mean for the quantitative assessment of such vessels. We also observed a wide variability of this score between the different

Table 1 Gastrin-releasing peptide-receptor expression in tumor-associated blood vessels and neoplastic cells of different tumor types in various anatomical sites: prevalence, receptor density, and vascular score

\begin{tabular}{|c|c|c|c|c|c|c|}
\hline \multirow{2}{*}{$\begin{array}{l}\text { Tissues } \\
\text { Tumor category }\end{array}$} & \multirow[b]{2}{*}{$n$} & \multicolumn{3}{|c|}{ GRP-receptors in tumor-associated blood vessels } & \multicolumn{2}{|c|}{ GRP-receptors in neoplastic cells } \\
\hline & & $\begin{array}{l}\text { Prevalence } \\
\text { (positive/total } \\
\text { cases }(\%))\end{array}$ & $\begin{array}{c}\text { Density }^{a} \\
(m e a n \pm \text { s.E.M. } \\
\text { (dpm/mg tissue)) }\end{array}$ & $\begin{array}{l}\text { Vascular } \\
\text { score }^{b}\end{array}$ & $\begin{array}{l}\text { Prevalence } \\
\text { (positive/total } \\
\text { cases }(\%))\end{array}$ & $\begin{array}{c}\text { Density } \\
\text { (mean } \pm \text { S.E.M. } \\
\text { (dpm/mg tissue)) }\end{array}$ \\
\hline \multicolumn{7}{|l|}{ Urinary tract cancer } \\
\hline $\begin{array}{l}\text { Invasive urothelial } \\
\text { carcinoma }\end{array}$ & 26 & $24 / 26(92 \%)$ & $1449 \pm 122$ & 1.69 & $0 / 26(0 \%)$ & - \\
\hline \multicolumn{7}{|l|}{ Lung cancer } \\
\hline Squamous carcinoma & 29 & $24 / 29(83 \%)$ & $1402 \pm 115$ & 1.28 & $2 / 29(7 \%)$ & 212,230 \\
\hline Adenocarcinoma & 17 & $10 / 17(59 \%)$ & $1024 \pm 112$ & 0.88 & $0 / 17(0 \%)$ & \\
\hline Large cell lung cancer & 2 & $0 / 2(0 \%)$ & & 0 & $0 / 2(0 \%)$ & \\
\hline Small cell lung cancer & 9 & $0 / 9(0 \%)$ & & 0 & $3 / 9(33 \%)$ & $1430 \pm 516$ \\
\hline Total & 57 & $34 / 57(60 \%)$ & $1301 \pm 94$ & 0.91 & $5 / 57(9 \%)$ & $664 \pm 335$ \\
\hline \multicolumn{7}{|l|}{ Colon cancer } \\
\hline Colorectal carcinoma & 46 & $34 / 44(88 \%)$ & $1299 \pm 84$ & 0.88 & $2 / 44(5 \%)$ & 240,335 \\
\hline \multicolumn{7}{|l|}{ Renal cell cancer } \\
\hline Clear cell carcinoma & 28 & $15 / 28(54 \%)$ & $1590 \pm 266$ & 0.82 & $9 / 28(32 \%)$ & $3013 \pm 904$ \\
\hline Papillary carcinoma & 4 & $2 / 4(50 \%)$ & 2181,578 & 1.0 & $0 / 4(0 \%)$ & \\
\hline Total & 32 & $17 / 32(53 \%)$ & $1561 \pm 243$ & 0.84 & $9 / 32(28 \%)$ & $3013 \pm 904$ \\
\hline \multicolumn{7}{|l|}{ Biliary tract cancer } \\
\hline Cholangiocarcinoma & 23 & $13 / 23(57 \%)$ & $1140 \pm 141$ & 0.69 & $2 / 23(9 \%)$ & 911,363 \\
\hline \multicolumn{7}{|l|}{ Breast cancer } \\
\hline $\begin{array}{l}\text { Invasive ductal } \\
\text { carcinoma }\end{array}$ & 113 & $35 / 113(31 \%)$ & $975 \pm 61$ & 0.39 & $77 / 113(68 \%)$ & $7276 \pm 797$ \\
\hline $\begin{array}{l}\text { Invasive lobular } \\
\text { carcinoma }\end{array}$ & 21 & $7 / 21(33 \%)$ & $862 \pm 93$ & 0.38 & $20 / 21(95 \%)$ & $4910 \pm 509$ \\
\hline Total & 134 & $42 / 134(31 \%)$ & $956 \pm 53$ & 0.39 & $97 / 134(72 \%)$ & $6797 \pm 651$ \\
\hline \multicolumn{7}{|l|}{ Prostate cancer } \\
\hline Acinar adenocarcinoma & 50 & $6 / 50(12 \%)$ & $1328 \pm 201$ & 0.14 & $48 / 50(96 \%)$ & $5315 \pm 856$ \\
\hline \multicolumn{7}{|c|}{ Ovarian cancer ${ }^{d}$} \\
\hline Primary cancers & 19 & $16 / 19(84 \%)$ & $2401 \pm 262$ & 1.7 & $5 / 19(26 \%)$ & $1155 \pm 301$ \\
\hline Metastases & 6 & $6 / 6(100 \%)$ & $2728 \pm 608$ & 2.6 & $0 / 6(0 \%)$ & - \\
\hline
\end{tabular}

\footnotetext{
${ }^{a}$ Vascular GRP-receptor density for each tumor was determined as a mean of the measurement of at least five positive vessels. The mean \pm S.E.M. (dpm/mg tissue) of these values is given for each tumor group.

${ }^{b}$ Each single tumor was graded according to the number or GRP-receptor positive tumor-associated blood vessels per area (0-3; see Materials and methods). The vascular score was defined as the mean of these grades in a given tumor group.

'Solely the GRP-receptor expressing neoplastic cells were quantified for their receptor density.

dData previously published by Fleischmann et al. (2007) shown for comparison.
} 
anatomical sites (Table 1) with the highest value for cancers of the urinary tract (score 1.69). It was similar to the one previously reported for ovarian cancers (score 1.7) but lower than the score of 2.6 as determined for metastases of ovarian cancer (Fleischmann et al. 2007). Following urinary tract cancers were lung cancers (score 0.91), colon cancers (score 0.88), kidney cancers (score 0.84 ), biliary tract cancers (score 0.69 ), breast cancers (score 0.39), and prostate cancers (score 0.14). Within a given anatomical site, the vascular scores of different tumor types could be similar like in the breast (invasive ductal carcinoma: 0.39 , invasive lobular carcinoma: 0.38 ; Table 1) or very different like in the lung (SCLC: 0 , adenocarcinoma: 0.88 , squamous carcinoma: 1.28 ; Table 1 ).

Morphological characteristics, distribution, and localization of GRP-receptor expressing tumor-associated blood vessels are summarized in Table 2. An overview of a receptor autoradiography of a typical case, an urothelial carcinoma, is shown in Fig. 1: most GRP-receptor positive blood vessels crossed the cut plane and appeared autoradiographically as black dots, oval structures or rings; occasionally, GRP-receptor positive blood vessels presented as straight vascular segments in the section. Notably, the GRP-receptor expressing vessels possessed a muscular wall; many of the GRP-receptor positive vessels were tortuous and showed no regularly layered wall, being therefore compatible with neoangiogenic tumor vessels (Fig. 2A-C); only few of the GRP-receptor positive vessels had well-organized vessel walls that would be compatible with pre-existing small veins (Fig. 2D-F). The muscular wall of the vessels was the principle site of GRP-receptor expression, with a moderate to high receptor density (Table 1) and with a homogeneous, circumferential, transmural distribution of the receptor. However, the limited resolution of the receptor autoradiography did not permit to conclusively evaluate a possible GRP-receptor expression of the bordering endothelial cells. In general, GRP-receptor positive vessels were small (diameter 30-120 $\mu \mathrm{m}$ ) and their lumina were collapsed; few were medium sized (diameter up to $2.5 \mathrm{~mm}$ ). The distribution of GRPreceptor expressing tumor-associated vessels was predominantly diffuse in the whole tumor sample, rarely restricted to circumscribed tumor areas in the form of 'hot spots'. When vascular GRP-receptors were present in a sample, only a part of the tumorassociated vessels expressed the receptors and positive and negative vessels could lie in close vicinity (Fig. 3A-C). GRP-receptor positive vessels were present within the tumor (Fig. 3D-F) and in the interface with the surrounding host tissue (Fig. 3G-I) within a rim of up to $3 \mathrm{~mm}$. However, as the tumor/host border is often poorly defined and only a minority of the samples evidently included peritumoral host tissue the accurate incidence of peritumoral GRP-receptor positive vessels could not be determined.

Inhibition curves were generated in successive sections using the radioligand ${ }^{125} \mathrm{I}$-[ $\left.\mathrm{Tyr}^{4}\right]$-bombesin in presence of increasing amounts of various related (bombesin, GRP) and non-related (somatostatin-28)

Table 2 Morphological characteristics, distribution, and localization of gastrin-releasing peptide-receptor expressing tumorassociated blood vessels

Characteristics of GRP-receptor expressing tumor-associated blood vessels

Vessel type In principle vessels with a muscular wall

Tortuous, poorly organized vessels, compatible

with neoangiogenic vessels ${ }^{(+++)}$

Typical veins ${ }^{(+)}$

Typical arteries $^{(-)}$

Vascular compartment of GRP-receptor expression

Muscular vessel wall with homogeneous, circumferential and transmural GRP-receptor expression

Vessel size

Vessel diameter: in general 30-120 $\mu \mathrm{m}$ (rarely up to $2.5 \mathrm{~mm}$ )

Longest vessel segment identified with GRP-receptor expression: $5 \mathrm{~mm}$

Distribution of vessels

Mostly diffuse in whole sample, in rare cases in circumscribed areas as 'hot spots'

GRP-receptor positive and negative vessels can lie in close vicinity

Localization of vessels

Intratumorally

Peritumorally (up to $3 \mathrm{~mm}$ from the tumor) at the interface with the surrounding host tissue

\footnotetext{
$(+++)$ Frequent type of GRP-receptor positive vessels.

${ }^{(+)}$Rare type of GRP-receptor positive vessels.

${ }^{(-)}$GRP-receptor negative vessels.
} 

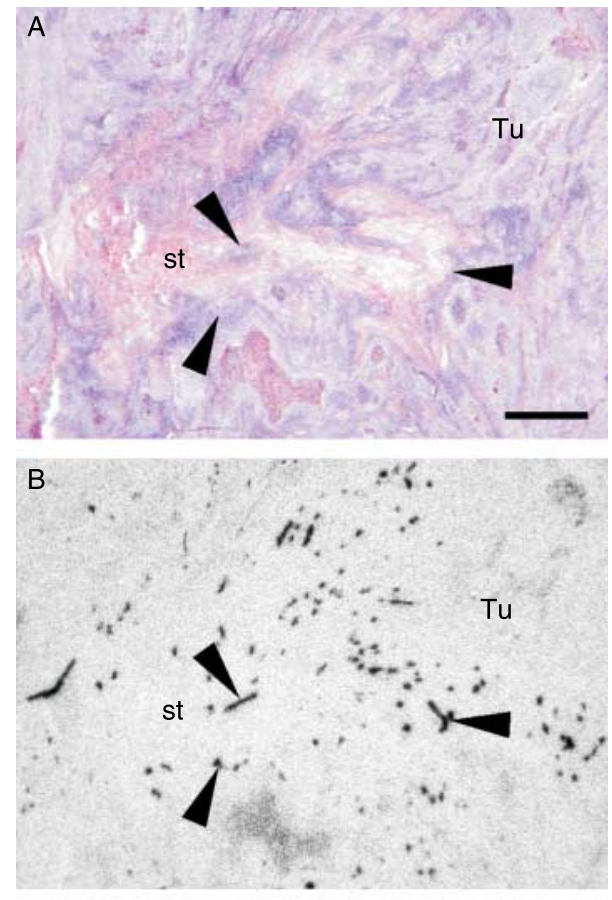

C

Figure 1 GRP-receptor expressing tumor-associated blood vessels in invasive urothelial carcinoma of the urinary tract. (A) H\&E stained section (bar $=1 \mathrm{~mm}$ ) of an invasive urothelial carcinoma with sheets of neoplastic cells $(\mathrm{Tu})$ and tumor stroma (st) containing blood vessels (three vessels indicated by arrowheads). (B) Autoradiogram showing total binding of ${ }^{125} \mathrm{I}$-[Tyr $\left.{ }^{4}\right]$-bombesin. Strongly labeled tumor-associated blood vessels presenting as black dots, lines, and tubular segments are present in the tumor. The neoplastic cells (Tu) are not labeled. (C) Control sections with non-specific binding.

unlabeled ligands for the pharmacological characterization of the GRP-receptor subtype in tumorassociated blood vessels. As shown in Fig. 4, the rank order of potencies at the receptor is characteristic for the GRP-receptor. Moreover, using the universal radioligand ${ }^{125} \mathrm{I}-\left[\mathrm{D}-\mathrm{Tyr}^{6}, \beta-\mathrm{Ala}^{11}, \mathrm{Phe}^{13}, \mathrm{Nle}^{14}\right]$-bombesin(6-14), displacement in the nanomolar range was always obtained with GRP, but not with NMB, further confirming the sole GRP-receptor expression in these vessels.
The other tumor tissue compartment with GRPreceptor expression was the neoplastic cell itself (Table 1). This compartment also revealed great differences in the prevalence of GRP-receptor expression between the different anatomical sites. While, as reported previously (Gugger \& Reubi 1999, Markwalder \& Reubi 1999), the vast majority of prostate and breast cancers tested in this study showed neoplastic cells overexpressing GRP-receptors (96 and $72 \%$ respectively), the neoplastic cells of urinary tract cancers completely lacked detectable GRP-receptors. Moderate expression of GRP-receptors was found in tumor cells of kidney cancers (28\%), while very low expression was found in biliary tract (9\%) and colon (5\%) cancers. Furthermore, differences in the prevalence of GRP-receptor positive neoplastic cells could be observed between tumor types of a given anatomical site. For instance, no GRP-receptors were found in adenocarcinomas of the lung while they were present in $33 \%$ of the SCLC (Table 1).

Most importantly, vascular GRP-receptors were not expressed in non-neoplastic tissues of the breast, prostate, kidney, colon, biliary tract, and urinary tract. However, single GRP-receptor positive vessels were present in non-neoplastic lung tissue (4/48) where they were associated with foci of inflammation. Additionally, as reported previously, GRP-receptors were expressed focally and in small amounts in the prostate stroma (Markwalder \& Reubi 1999), in the muscular layers of the colon (Rettenbacher \& Reubi 2001) and urinary tract at variable levels and in the neural plexus of the colon (Rettenbacher \& Reubi 2001). Also the epithelial compartment in prostatic intraepithelial neoplasia (Markwalder \& Reubi 1999) and in some cases of non-neoplastic prostate and breast (Gugger \& Reubi 1999) showed focal GRP-receptor expression while the epithelial components in the remaining non-neoplastic tissues (lung, kidney, biliary tract, and urinary tract) lacked GRP-receptors.

\section{Discussion}

The tumor vascular bed is important for tumor progression because tumors exceeding 1-2 mm need their own blood supply for further growth (Auguste et al. 2005). Development and function of the tumor vascular bed are regulated by a large number of mechanisms characterized recently at the molecular level (Auguste et al. 2005). Newly, also GRP and its receptor have been shown to play a role in the vascular bed in specific cancer models (Levine et al. 2003a,b, Bajo et al. 2004, Heuser et al. 2005, Kanashiro et al. 2005, 2007, Stangelberger et al. 2005, 

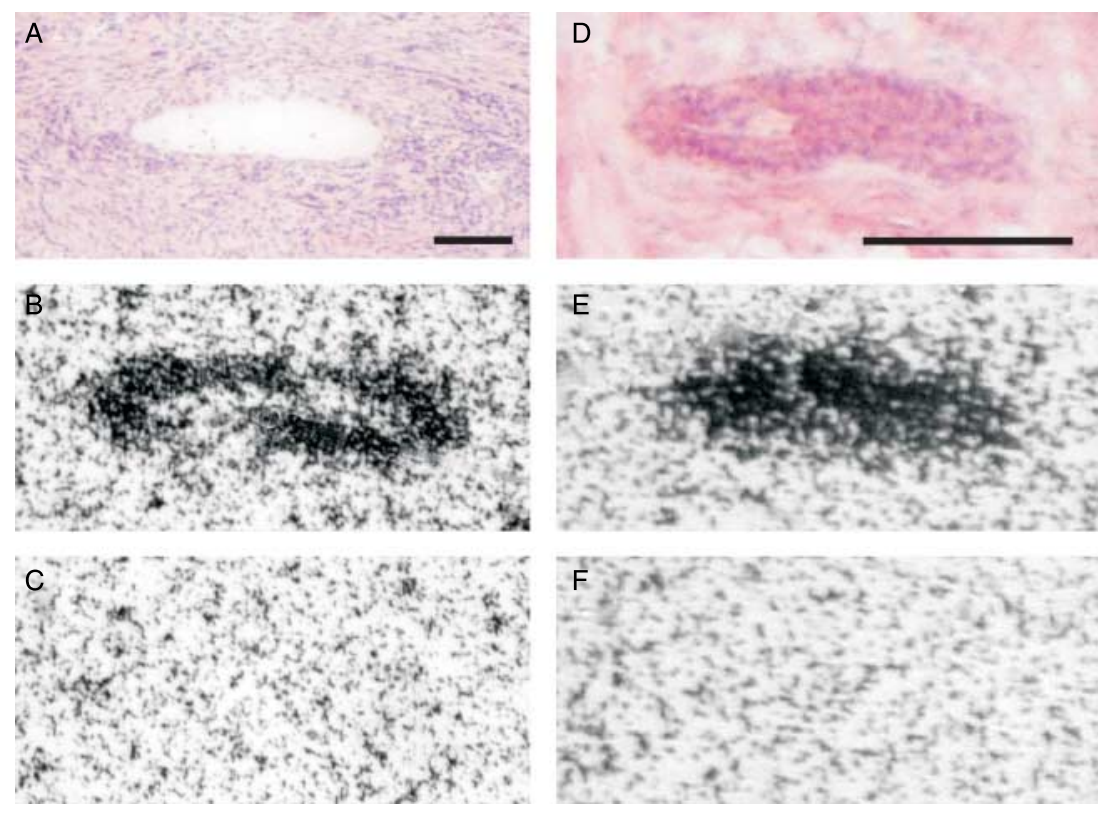

Figure 2 GRP-receptor expressing tumor-associated blood vessels possess a muscular wall. Many are vascular structures compatible with neoangiogenic vessels $(A-C)$; rarely are they pre-existing small veins $(D-F)$. (A and $D)$ : H\&E-stained sections (bars $=0.1 \mathrm{~mm}$ ) showing detailed features of tumor-associated blood vessels. $(A)$ : a colon cancer-associated blood vessel of medium size without well organized, layered muscular wall, compatible with a neoangiogenic vessel. (D): a breast cancer-associated vein with a well organized, layered muscular vessel wall. (B and E): autoradiograms showing total binding of ${ }^{125} \mathrm{I}-\left[\mathrm{T}_{\mathrm{r}} \mathrm{H}^{4}\right]-\mathrm{bombesin}$. Strong labeling of the muscular vessel walls in $\mathrm{B}$ and in $\mathrm{E}$. ( $\mathrm{C}$ and $\mathrm{F})$ : control sections with non-specific binding.

Kang et al. 2007), suggesting a putative role in human primary cancers as well. The present report is the first study evaluating systematically a large number of common human cancers from various anatomical sites specifically for GRP-receptor expression in their tumor vascular beds. A main message of this study is that tumors expressing GRP-receptors in their vascular bed can be detected in all evaluated anatomical sites. Importantly, however, the incidence of these receptor positive vessels, reflected by their prevalence and the vascular score, varied broadly between the anatomical sites: urinary tract cancer had the highest prevalence (92\%) and vascular score (1.69) while prostate cancer displayed the lowest values (prevalence: $12 \%$; score: 0.14 ). These values could also vary between different tumor types within a given anatomical site as shown in the lung for SCLC (prevalence: 0\%; score: 0), adenocarcinomas (prevalence: 59\%; score: 0.88 ) and squamous carcinomas (prevalence: $83 \%$; score: 1.28). Together, these data suggest that GRP-receptor expression in the tumor vascular bed may be a phenomenon related to the specific tumor type rather than a universal and uniform regulatory mechanism in the tumor vascular bed per se. Further functional evaluation of vasculotropic effects of GRP in tumors should therefore consider these inter-tumoral differences and preferentially choose tumor models displaying the highest amounts of vascular GRPreceptors related to urothelial cancer or, as previously shown by our group, to ovarian cancers (Fleischmann et al. 2007).

Blood vessels in the tumor bed are of different origins including preexisting veins and arteries incorporated in the growing tumor mass and newly formed neoangiogenic blood vessels with abnormally organized walls (Jain 2003, Auguste et al. 2005, Dome et al. 2007). In our study, GRP-receptor positive blood vessels were mostly small and characteristically had a muscular wall. In general, these tumor-associated vessels ran tortuous, had no specific structure of the wall and were morphologically compatible with neoangiogenic vessels. Notably, the muscular wall of these vessels was the site of GRP-receptor expression with moderate to high receptor densities in a homogeneous, transmural receptor distribution. Only rarely did GRP-receptor positive vessels present morphologically as typical small veins. What may be the function of these tumoral vessels expressing GRPreceptors? First, tumor-associated GRP-receptor positive vessels might be involved in tumoral hemodynamics. Data in line with this concept are that bombesin and GRP physiologically regulate the vascular tone (Bjenning et al. 1991, Luu et al. 1993, Clive et al. 2001) and that GRP-receptors are expressed 

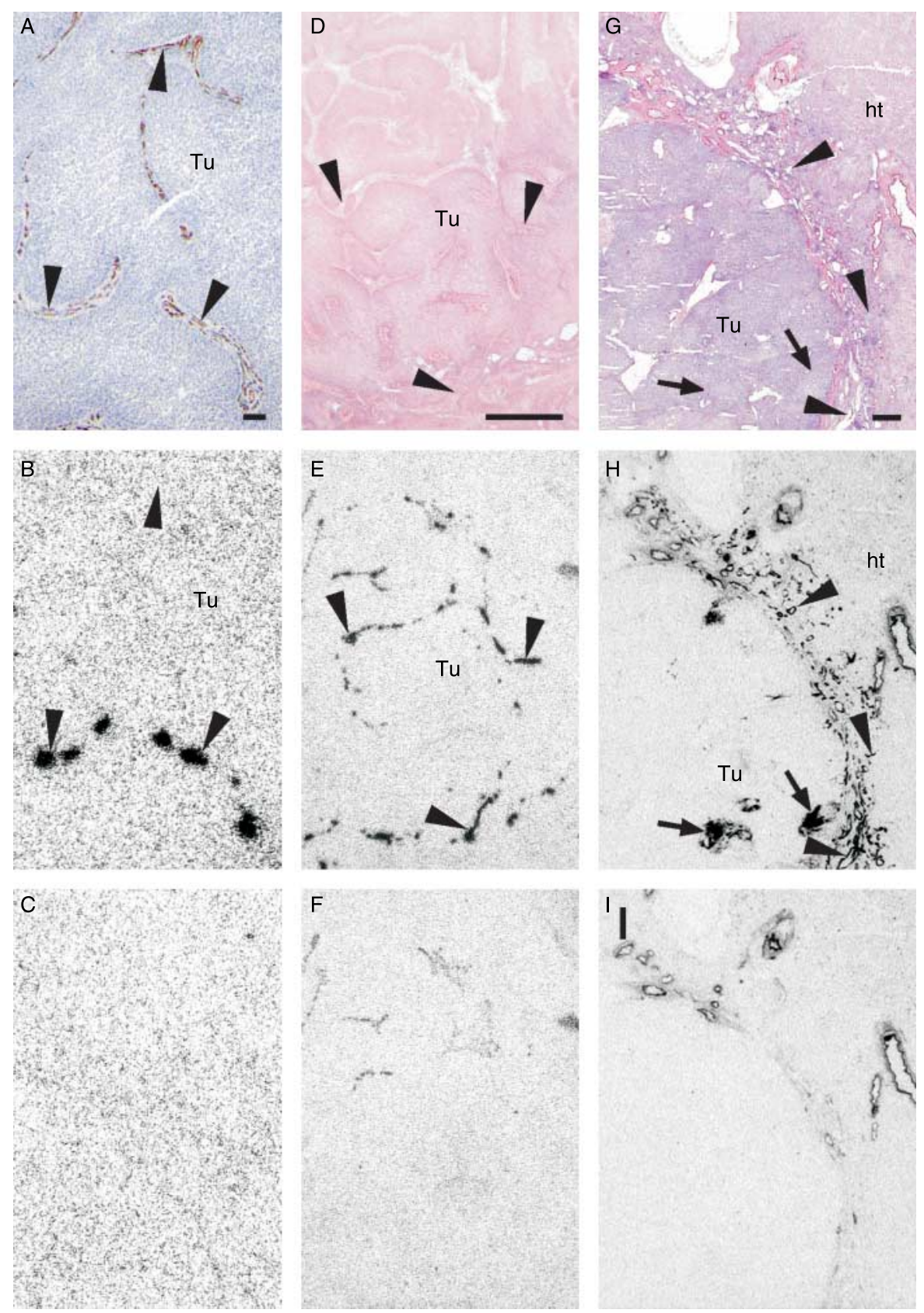

Figure 3 Distribution and localization of GRP-receptor positive vessels in the tumor vascular bed. (A-C): GRP-receptors are expressed only in a part of the tumor-associated blood vessels. (D-I): GRP-receptor expressing tumor-associated blood vessels are present intratumorally (D-F) and/or at the interface with the surrounding host tissue (G-I). (A): invasive urothelial carcinoma (Tu) showing immunohistochemically (CD34) brown stained endothelium of blood vessels (three indicated by arrowheads), which run within narrow stromal septa; bar $=0.1 \mathrm{~mm}$. (B): autoradiogram showing total binding of ${ }^{125} \mathrm{I}-\left[\mathrm{T}_{\mathrm{Tr}} \mathrm{H}^{4}\right.$-bombesin. The vessels (three indicated by arrowheads) are only labeled in the lower part of the sample but not in the upper part. The neoplastic cells of the tumor (Tu) are not labeled. (C): control section showing non-specific binding. (D and G): H\&E stained sections; bars =1 mm. (D): invasive urothelial carcinoma (Tu) composed of solid growing neoplastic cells and intratumoral blood vessels (three vessels indicated by arrowheads); (G): clear cell renal carcinoma (Tu) showing solid growing neoplastic cells (two histopathologically unremarkable areas indicated by arrows). The tumor is well demarcated from the surrounding host tissue (ht) and there are numerous blood vessels at the tumor/host interface (three indicated by arrowheads). $(E$ and $H)$ : autoradiograms showing total binding of ${ }^{125}$ - $\left[\right.$ Tyr $\left.^{4}\right]$-bombesin. Strongly labeled tumor-associated blood vessels presenting as black dots, lines or tubular segments are present intratumorally in $\mathrm{E}$ and at the interface of the tumor ( $\mathrm{Tu}$ ) with the host tissue (ht) in $\mathrm{H}$ (three vessels of each sample indicated by arrowheads). The neoplastic cells are focally labeled in $\mathrm{H}$ (arrows) but not in $\mathrm{E}$. ( $\mathrm{F}$ and $\mathrm{I})$ : control sections with non-specific binding. 


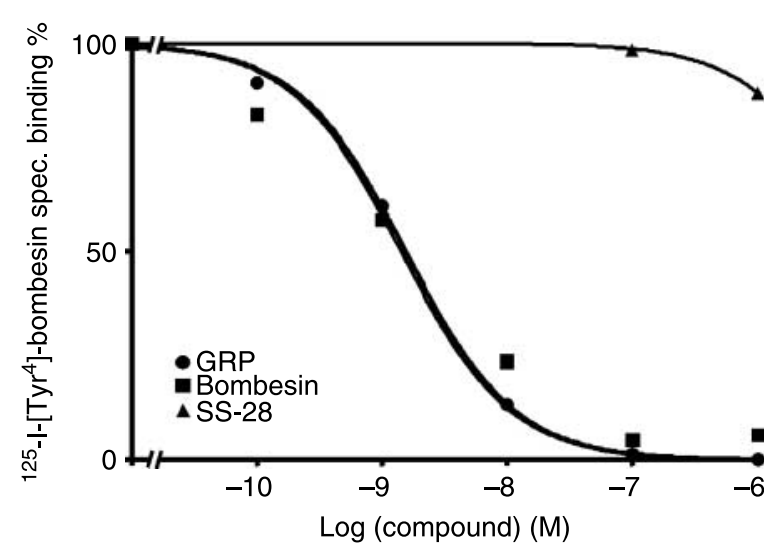

Figure 4 Competition curves in a representative GRP-receptor expressing tumor-associated vessel in colon cancer using ${ }^{125} \mathrm{I}-\left[\mathrm{Tyr}^{4}\right]$-bombesin as radioligand. Successive tissue sections were incubated with the radioligand and increasing concentrations of unlabeled GRP (O), bombesin ( $\boldsymbol{\square})$, and somatostatin-28 (SS-28; $\boldsymbol{\Delta}$ ). High-affinity displacement of the tracer was found with GRP and bombesin, whereas SS-28 induced only displacement at lower affinity. Non-specific binding was subtracted from all values. The observed rank order of potencies of these analogs is compatible with the GRP-receptor subtype.

in the blood pressure controlling vascular muscle cells. Second, these GRP-receptors might play a role in tumor neoangiogenesis. Indeed, previous functional studies have been able to link GRP to angiogenesis: at the molecular level, GRP up-regulates pro-angiogenic factors such as vascular endothelial growth factor (VEGF) in prostate and endometrial cancer in vitro (Levine et al. 2003a,b) and in neuroblastoma in vivo (Kang et al. 2007) while GRP antagonists reduce such factors in glioblastoma (Kanashiro et al. 2005), prostate (Stangelberger et al. 2005), breast (Bajo et al. 2004), and non-small cell lung (Kanashiro et al. 2007) cancer. Correspondingly, on cellular and tissue level, GRP stimulates endothelial cell migration and cord formation in vitro as well as angiogenesis in vivo (Martinez et al. 2005), whereas GRP-receptor antagonists reverse these effects and furthermore diminish the tumoral blood vessel density in animal models of breast (Bajo et al. 2004) and renal cell (Heuser et al. 2005) cancer. Although speculative, the particular GRP-receptor expression in the muscular coat of tumor-associated vessels might trigger a crucial process in neoangiogenesis, namely the vessel wall formation by recruitment of their cellular elements, the pericytes/smooth muscle cells (Jain 2003). The important cellular actions in this process are proliferation, migration, and morphogenesis, and, notably, these cellular properties have been shown to be stimulated by GRP (Bunnett 1994, Kim et al. 1997,
Yule \& White 1999, Jensen et al. 2001). Consequently, the detection of this particular GRP-receptor expression in the muscular coat of tumor-associated blood vessels might open the way for new insights in tumoral hemodynamics or alternatively add new aspects to the pro-angiogenic properties of GRP (Heuser et al. 2005, Martinez 2006), in particular to the understanding of neoangiogenic blood vessel maturation.

The other tumor tissue component expressing GRPreceptors investigated in the present study was the neoplastic cell itself. Of all tested tumors, only prostate and breast cancers expressed large amounts of GRPreceptors in this component, as previously reported (Gugger \& Reubi 1999, Markwalder \& Reubi 1999). Those, however, had very few vascular GRP-receptors. Conversely, urinary tract tumors, with a high expression of GRP-receptors in vessels, had none in the neoplastic cells. One can therefore observe a trend for GRP-receptor deficient tumors (e.g. urinary tract and serous ovarian (Fleischmann et al. 2007) cancers) to express large amounts of GRP-receptors in their tumor vascular bed, and for GRP-receptor expressing tumors (e.g. prostate and breast cancers) to lack GRPreceptors in their vascular bed. Consequently, caution should be given when assessing the cellular origin of GRP-receptors detected on mRNA or protein level in homogenates of tumor samples.

The results of our study may be of potential clinical relevance. Cancer targeting in general and GRPreceptor targeted cancer imaging and therapy in particular has attracted a considerable amount of interest over the last years (de Visser et al. 2008). These approaches primarily focused on the neoplastic cancer cells themselves. However, alternative strategies have recently been explored by evaluating in particular the targeting of the tumor vascular bed (Thorpe et al. 2003, Brack et al. 2004). The key to successful selective molecular vascular targeting is the identification of target molecules being considerably expressed in the tumoral vasculature. Vascular GRPreceptors in urothelial cancers may meet these criteria as would also ovarian cancers (Fleischmann et al. 2007). Those cancers should be the first to be selected for in vivo targeting in patients. Whether other cancers with less GRP-receptor positive tumoral vessels (lung, kidney or colon cancers) would also apply for such an approach, should be evaluated in a second step. For angiodestructive therapies, radiolabeled or cytotoxic bombesin receptor agonists (Zhang et al. 2004, 2007, Engel et al. 2005, Nock et al. 2005, Lantry et al. 2006, Moody et al. 2006, Patel et al. 2006, de Visser et al. 2007, Waser et al. 2007) and their antagonists 
(Cescato et al. 2008) may be delivered specifically to tumor vessels in order to damage them, causing rapid shutdown of vascular function and leading to tumor necrosis with subsequent tumor control. In fact, a similar concept has already been successfully applied in animal models using annexin A1 as a specifically expressed vascular target for radioimmunotherapy in tumors (Oh et al. 2004). Alternatively, bombesin receptor antagonists might be used for angiostatic therapies preventing tumor progression by inhibition of neovascularization. Such anti-vascular effects of bombesin antagonists have recently been reported in animal models of breast (Bajo et al. 2004) and renal cell (Heuser et al. 2005) cancer. Even more powerful, a dual vascular targeting may be conceivable, supplementing and optimizing anti-VEGF directed antivascular therapies in urinary tract cancer (Mitra et al. 2006) by synergistic effects of a vascular GRP-receptor targeting. If feasible, in vivo imaging of the tumor vascular bed might in future expand the clinical applications of vascular GRP-receptor targeting.

\section{Declaration of interest}

No conflict of interest to declare.

\section{Funding}

This research did not receive any specific grant from any funding agency in the public, commercial or not-for-profit sector.

\section{References}

Auguste P, Lemiere S, Larrieu-Lahargue F \& Bikfalvi A 2005 Molecular mechanisms of tumor vascularization. Critical Reviews in Oncology/Hematology 54 53-61.

Bajo AM, Schally AV, Groot K \& Szepeshazi K 2004 Bombesin antagonists inhibit proangiogenic factors in human experimental breast cancers. British Journal of Cancer 90 245-252.

Bjenning C, Farrell AP \& Holmgren S 1991 Bombesin-like immunoreactivity in skates and the in vitro effect of bombesin on coronary vessels from the longnose skate, Raja rhina. Regulatory Peptides 35 207-219.

Bologna M, Festuccia C, Muzi P, Biordi L \& Ciomei M 1989 Bombesin stimulates growth of human prostatic cancer cells in vitro. Cancer 63 1714-1720.

Brack SS, Dinkelborg LM \& Neri D 2004 Molecular targeting of angiogenesis for imaging and therapy. European Journal of Nuclear Medicine and Molecular Imaging 31 1327-1341.

Bunnett N 1994 Gastrin-releasing peptide. In Gut Peptides: Biochemistry and Physiology, pp 423-445. Eds JH Walsh \& GJ Dockray. New York: Raven Press, Ltd.
Cescato R, Maina T, Nock B, Nikolopoulou A, Charalambidis D, Piccand V \& Reubi JC 2008 Bombesin receptor antagonists may be preferable to agonists for tumor targeting. Journal of Nuclear Medicine 49 318-326.

Clive S, Jodrell D \& Webb D 2001 Gastrin-releasing peptide is a potent vasodilator in humans. Clinical Pharmacology and Therapeutics 69 252-259.

Cuttitta F, Carney DN, Mulshine J, Moody TW, Fedorko J, Fischler A \& Minna JD 1985 Bombesin-like peptides can function as autocrine growth factors in human small-cell lung cancer. Nature 316 823-826.

Dome B, Hendrix MJ, Paku S, Tovari J \& Timar J 2007 Alternative vascularization mechanisms in cancer: pathology and therapeutic implications. American Journal of Pathology 170 1-15.

Engel JB, Schally AV, Halmos G, Baker B, Nagy A \& Keller G 2005 Targeted cytotoxic bombesin analog AN-215 effectively inhibits experimental human breast cancers with a low induction of multi-drug resistance proteins. Endocrine-Related Cancer 12 999-1009.

Fleischmann A, Laderach U, Friess H, Buechler MW \& Reubi JC 2000 Bombesin receptors in distinct tissue compartments of human pancreatic diseases. Laboratory Investigation 80 1807-1817.

Fleischmann A, Waser B, Gebbers JO \& Reubi JC 2005 Gastrin-releasing peptide receptors in normal and neoplastic human uterus: involvement of multiple tissue compartments. Journal of Clinical Endocrinology and Metabolism 90 4722-4729.

Fleischmann A, Waser B \& Reubi JC 2007 Overexpression of gastrin-releasing peptide receptors in tumor-associated blood vessels of human ovarian neoplasms. Cellular Oncology 29 421-433.

Gugger M \& Reubi JC 1999 Gastrin-releasing peptide receptors in non-neoplastic and neoplastic human breast. American Journal of Pathology 155 2067-2076.

Heuser M, Schlott T, Schally AV, Kahler E, Schliephake R, Laabs SO \& Hemmerlein B 2005 Expression of gastrin releasing peptide receptor in renal cell carcinomas: a potential function for the regulation of neoangiogenesis and microvascular perfusion. Journal of Urology 173 2154-2159.

Jain RK 2003 Molecular regulation of vessel maturation. Nature Medicine 9 685-693.

Jensen JA, Carroll RE \& Benya RV 2001 The case for gastrin-releasing peptide acting as a morphogen when it and its receptor are aberrantly expressed in cancer. Peptides 22 689-699.

Jensen RT, Battey JF, Spindel ER \& Benya RV 2008 International Union of Pharmacology. LXVIII. Mammalian bombesin receptors: nomenclature, distribution, pharmacology, signaling, and functions in normal and disease states. Pharmacological Reviews $601-42$. 
Kanashiro CA, Schally AV, Cai RZ \& Halmos G 2005 Antagonists of bombesin/gastrin-releasing peptide decrease the expression of angiogenic and anti-apoptotic factors in human glioblastoma. Anticancer Research 16 159-165.

Kanashiro CA, Schally AV, Zarandi M, Hammann BD \& Varga JL 2007 Alterations of EGFR/HER, angiogenesis and apoptosis pathways after therapy with antagonists of growth hormone releasing hormone and bombesin in nonsmall cell lung cancer. International Journal of Oncology 30 1019-1028.

Kang J, Ishola TA, Baregamian N, Mourot JM, Rychahou PG, Evers BM \& Chung DH 2007 Bombesin induces angiogenesis and neuroblastoma growth. Cancer Letters 253 273-281.

Kim JS, McKinnis VS \& White SR 1997 Migration of guinea pig airway epithelial cells in response to bombesin analogues. American Journal of Respiratory Cell and Molecular Biology 16 259-266.

Korner M \& Reubi JC 2007 NPY receptors in human cancer: a review of current knowledge. Peptides 28 419-425.

Lantry LE, Cappelletti E, Maddalena ME, Fox JS, Feng W, Chen J, Thomas R, Eaton SM, Bogdan NJ, Arunachalam T et al. 2006 177Lu-AMBA: synthesis and characterization of a selective 177Lu-labeled GRP-R agonist for systemic radiotherapy of prostate cancer. Journal of Nuclear Medicine 47 1144-1152.

Levine L, Licci JA III, Townsend CM Jr \& Hellmich MR $2003 a$ Expression of gastrin-releasing peptide receptors in endometrial cancer. Journal of the American College of Surgeons 196 898-904.

Levine L, Lucci JA III, Pazdrak B, Cheng JZ, Guo YS, Townsend CM Jr \& Hellmich MR 2003b Bombesin stimulates nuclear factor kappa $\mathrm{B}$ activation and expression of proangiogenic factors in prostate cancer cells. Cancer Research 63 3495-3502.

Luu TN, Chester AH, O’Neil GS, Tadjkarimi S, Pepper JR \& Yacoub MH 1993 Different responses of the human gastroepiploic and internal mammary arteries to vasoactive peptides. American Journal of Physiology 264 H583-H587.

Markwalder R \& Reubi JC 1999 Gastrin-releasing peptide receptors in the human prostate: relation to neoplastic transformation. Cancer Research 59 1152-1159.

Martinez A 2006 A new family of angiogenic factors. Cancer Letters 236 157-163.

Martinez A, Zudaire E, Julian M, Moody TW \& Cuttitta F 2005 Gastrin-releasing peptide (GRP) induces angiogenesis and the specific GRP blocker 77427 inhibits tumor growth in vitro and in vivo. Oncogene 24 4106-4113.

Mitra AP, Datar RH \& Cote RJ 2006 Molecular pathways in invasive bladder cancer: new insights into mechanisms, progression, and target identification. Journal of Clinical Oncology 24 5552-5564.

Moody TW, Sun LC, Mantey SA, Pradhan T, Mackey LV, Gonzales N, Fuselier JA, Coy DH \& Jensen RT 2006 In vitro and in vivo antitumor effects of cytotoxic camptothecin-bombesin conjugates are mediated by specific interaction with cellular bombesin receptors. Journal of Pharmacology and Experimental Therapeutics 318 1265-1272.

Narazaki M \& Tosato G 2005 Targeting coagulation to the tumor microvasculature: perspectives and therapeutic implications from preclinical studies. Journal of the National Cancer Institute 97 705-707.

Nock BA, Nikolopoulou A, Galanis A, Cordopatis P, Waser B, Reubi JC \& Maina T 2005 Potent bombesin-like peptides for GRP-receptor targeting of tumors with 99mTc: a preclinical study. Journal of Medicinal Chemistry 48 100-110.

Oh P, Li Y, Yu J, Durr E, Krasinska KM, Carver LA, Testa JE \& Schnitzer JE 2004 Subtractive proteomic mapping of the endothelial surface in lung and solid tumours for tissue-specific therapy. Nature 429 629-635.

Otrock ZK, Mahfouz RA, Makarem JA \& Shamseddine AI 2007 Understanding the biology of angiogenesis: review of the most important molecular mechanisms. Blood Cells, Molecules \& Diseases 39 212-220.

Patel O, Shulkes A \& Baldwin GS 2006 Gastrin-releasing peptide and cancer. Biochimica et Biophysica Acta 1766 23-41.

Rettenbacher M \& Reubi JC 2001 Localization and characterization of neuropeptide receptors in human colon. Naunyn-Schmiedeberg's Archives of Pharmacology 364 291-304.

Reubi JC \& Waser B 2003 Concomitant expression of several peptide receptors in neuroendocrine tumours: molecular basis for in vivo multireceptor tumour targeting. European Journal of Nuclear Medicine and Molecular Imaging 30 781-793.

Reubi JC, Schaer JC, Laissue JA \& Waser B 1996 Somatostatin receptors and their subtypes in human tumors and in peritumoral vessels. Metabolism $\mathbf{4 5}$ 39-41.

Reubi JC, Wenger S, Schmuckli-Maurer J, Schaer JC \& Gugger M 2002 Bombesin receptor subtypes in human cancers: detection with the universal radioligand (125)I[D-TYR(6), $\beta$-ALA(11), PHE(13), NLE(14)] bombesin(6-14). Clinical Cancer Research 8 1139-1146.

Stangelberger A, Schally AV, Varga JL, Hammann BD, Groot K, Halmos G, Cai RZ \& Zarandi M 2005 Antagonists of growth hormone releasing hormone (GHRH) and of bombesin/gastrin releasing peptide (BN/GRP) suppress the expression of VEGF, bFGF, and receptors of the EGF/HER family in PC-3 and DU-145 human androgen-independent prostate cancers. Prostate 64 303-315.

Thorpe PE, Chaplin DJ \& Blakey DC 2003 The first international conference on vascular targeting: meeting overview. Cancer Research 63 1144-1147.

Vigna SR, Mantyh CR, Giraud AS, Soll AH, Walsh JH \& Mantyh PW 1987 Localization of specific binding sites for bombesin in the canine gastrointestinal tract. Gastroenterology 93 1287-1295. 
de Visser M, Bernard HF, Erion JL, Schmidt MA, Srinivasan A, Waser B, Reubi JC, Krenning EP \& de Jong M 2007 Novel (111)In-labelled bombesin analogues for molecular imaging of prostate tumours. European Journal of Nuclear Medicine and Molecular Imaging 34 1228-1238.

de Visser M, Verwijnen SM \& de Jong M 2008 Update: improvement strategies for peptide receptor scintigraphy and radionuclide therapy. Cancer Biotherapy \& Radiopharmaceuticals 23 137-157.

Waser B, Eltschinger V, Linder K, Nunn A \& Reubi JC 2007 Selective in vitro targeting of GRP and NMB receptors in human tumours with the new bombesin tracer (177)LuAMBA. European Journal of Nuclear Medicine and Molecular Imaging 34 95-100.

Yano T, Pinski J, Groot K \& Schally AV 1992 Stimulation by bombesin and inhibition by bombesin/ gastrin-releasing peptide antagonist RC-3095 of growth of human breast cancer cell lines. Cancer Research $\mathbf{5 2}$ 4545-4547.

Yule KA \& White SR 1999 Migration of 3T3 and lung fibroblasts in response to calcitonin gene-related peptide and bombesin. Experimental Lung Research 25 261-273.

Zhang H, Chen J, Waldherr C, Hinni K, Waser B, Reubi JC \& Maecke HR 2004 Synthesis and evaluation of bombesin derivatives on the basis of pan-bombesin peptides labeled with indium-111, lutetium-177, and yttrium-90 for targeting bombesin receptor-expressing tumors. Cancer Research 64 6707-6715.

Zhang H, Schuhmacher J, Waser B, Wild D, Eisenhut M, Reubi JC \& Maecke HR 2007 DOTA-PESIN, a DOTAconjugated bombesin derivative designed for the imaging and targeted radionuclide treatment of bombesin receptorpositive tumours. European Journal of Nuclear Medicine and Molecular Imaging 34 1198-1208. 